\title{
Contextos Histórico-Políticos, Desigualdad y Poder en Procesos Culturales-Patrimoniales
}

\author{
Mónica Beatriz Rotman \\ Universidad de Buenos Aires (UBA), Buenos Aires, Cidade autônoma de Buenos \\ Aires, Argentina \\ E-mail:mbr30855@gmail.com
}




\section{Resumen}

Analizamos comparativamente en este trabajo dos casos, ubicados en la Ciudad de Buenos Aires y originados a fines de los 60': el "Museo de la Ciudad de Buenos Aires" con la "Feria de San Pedro Telmo" (de Antigüedades) y las "Ferias Artesanales del "Sistema de Ferias", dependientes del entonces Municipio de la Ciudad, hoy Gobierno Autónomo. Culminamos su examen en 1976 cuando se instala en el país la última dictadura militar. La propuesta se ha ubicado en el campo de la cultura y el patrimonio, interesándonos en las "marcas" que el contexto social, político e ideológico en el cual se insertan los ámbitos examinados, imprime sobre los mismos, así como en las formas en que se manifiesta la desigualdad y se ejerce el poder en dicho campo; aclarando que durante el lapso abarcado en la investigación (y salvo excepcionales momentos), el país se encontraba bajo gobiernos de facto.

Palabras clave: Museo de la Ciudad de Buenos Aires. Ferias Artesanales. Campo cultural-patrimonial. Contexto histórico-político. Legitimidad y poder.

\section{Resumo}

Analisamos comparativamente neste trabalho dois casos, localizados na cidade de Buenos Aires e originados no final dos anos de 1960: o "Museo de la Ciudad de Buenos Aires" com a "Feria de San Pedro Telmo" (de Antiguidades) $e$ as "Ferias Artesanales del Sistema de Ferias", dependentes do Município da Cidade durante essa data, atual Governo Autónomo. Culminamos a pesquisa em 1976, momento em que se instala no país a última ditadura militar. A proposta situa-se dentro do campo da cultura e do patrimônio, colocando foco nas "marcas" que o contexto social, político e ideológico, no qual se insertam os âmbitos examinados, imprime sob eles, assim como nas formas em que se manifesta a desigualdade e se exerce o poder no campo sinalado, aclarando que durante o lapso abrangido na pesquisa (e salvo curtos períodos), o país encontrava-se sob o comando do governo militar.

Palavras-chave: Museu da Cidade de Buenos Aires. Férias Artesanais. Campo Culturale Patrimonial. Contexto Histórico e Político. Legitimidade e Poder. 


\section{Introducción}

— 1 campo patrimonial puede ser aprehendido desde sus diferentes dimensiones. Y, si bien durante los últimos años el área no se caracterizado por sus avances en cuestiones teóricas (luego de los relevantes aportes que se produjeron a fines de los 70'y durante los 80’ (los cuales modificaron radicalmente concepciones, conceptos, e inauguraron una nueva etapa en el tema) ello posibilitó una apertura en la temática y trabajos que contemplaran tales transformaciones; cabe señalar por lo demás, que han proliferado los estudios de caso. La visibilidad cobrada por el tema y su persistente y continua manifestación en estos tiempos ha ido en aumento. Y, si bien entendemos que es preciso continuar con un proceso de actualización teórica, también observamos que, examinada con atención, parte de la profusa casuística nos orienta y estimula en nosotros nuevas interrogaciones, ya sobre otras bases; conduciéndonos hacia una reflexión sobre articulaciones, vinculaciones conceptuales y especificidades, que complejizan presupuestos sobre la dinámica del campo, a la vez que informan del carácter heterogéneo, de las particularidades de los procesos patrimoniales locales/nacionales.

Por otra parte, hace pocas décadas que "los investigadores de los países periféricos han visibilizado y dado entidad a las Antropologías del Sur" (Krotz, 1996, p. 8) ${ }^{1}$, en contrapunto y condiciones de desigualdad respecto de aquellas hegemónicas producidas en los países centrales. Pero además, han puesto de manifiesto que tales Antropologías del Sur no son homogéneas, señalando sus particularidades. De la misma manera, entendemos que, así como se ha establecido un "corpus patrimonial", que sienta bases, pautas, procedimientos, preceptos, regulando el campo y "naturalizando" tales regulaciones, con 
aplicabilidad hacia la mayoría de los estados, así también, éste entra en contacto con distintas y heterogéneas realidades, en las cuales "lo local" lleva a la configuración de situaciones específicas (que pueden no encajar en el canon); éstas, no obstante producen conocimiento y aportan a la problemática. Por otra parte, en la actualidad y en algunos tópicos patrimoniales, continúan las narraciones, propuestas y discursos" hegemónicos", que operan encubriendo, disimulando desigualdades y/o propiciando jerarquizaciones ${ }^{2}$. A nivel global, la figura más visible y evidente está representada por los Organismos Internaciones (particularmente UNESCO) que intervienen sobre ciertos temas y bajo las constricciones de las potencias centrales. No obstante, nos interesa en este trabajo, "la hegemonía operando a nivel local".

A partir de lo dicho, nos interesa retomar dos casos de nuestro país (Argentina), acaecidos en la Ciudad de Buenos Aires, aproximadamente cuatro décadas atrás. Planteamos su comparación, atendiendo a: la relevancia e imbricación del "contexto" históricopolítico, en nuestro estudio implicando gobiernos de facto: sus rígidas y represivas normativas respecto de los fenómenos objeto de análisis; un comportamiento errático, marcado por la influencia de las relaciones personales; la fluctuación en la imposición de las reglas, acorde a la cercanía y confianza inspiradas en tales vínculos; la aplicación de una doble vara; la suma certeza respecto de la identificación de los "ámbitos legítimos de la cultura"; la negación de manifestaciones y expresiones de "lo cultural" que no se encuadran en los moldes establecidos; los prejuicios sobre sujetos, espacios y eventos no convencionales; la clausura de toda reflexión sobre los campos de la cultura y el patrimonio; la convicción del "enemigo interno", e identificado con el "otro no reconocido". Entendemos que "el contexto", no es algo externo a la construcción de conocimiento antropológico, sino que se compone de "elementos intrínsecamente constitutivos del mismo". Por tanto, lejos de ser un marco, estructura y/o constriñe los hechos y también las interpretaciones de los investigadores. Siendo la producción de conocimiento científico un proceso de creación cultural, no puede ser analizado solo como sistema simbólico, separado de los otros aspectos de la realidad social más comprehensiva (Krotz, 1993, 
p. 8). Asimismo, la dimensión comparativa atiende a los mecanismos mediante los cuales se manifiesta la "desigualdad" en el campo de la cultura y el patrimonio, así como las formas que asume el ejercicio del poder en hechos culturales- patrimoniales, inmersos en una realidad político-económica configurada mayormente por gobiernos de facto, involucrando concepciones, definiciones, prácticas, gestiones, que delinean y modelan la lógica de los procesos y su desenlace.

Los casos a tratar en este artículo involucran al "Museo de la Ciudad" y la "Feria de San Pedro Telmo" y a las "Ferias Artesanales de la Ciudad de Buenos Aires" (integrantes ésta últimas del "Sistema de Ferias", dependientes precozmente del entonces Municipio de la Ciudad, hoy Gobierno Autónomo) $)^{3}$.

\section{Memoria e Historia, Soportes de la Cultura y el Patrimonio (¿una articulación no conflictiva?)}

La creación del Museo de la Ciudad y de la Feria de San Pedro Telmo guardan relación con la problemática de los Centros Históricos y la preservación patrimonial ${ }^{4}$, en un período (fines de los 60'), en el cual si bien el patrimonio histórico-cultural no formaba parte significativa de la agenda gubernamental, se comienzan a configurar políticas patrimoniales; experiencias en tensión con los procesos políticos de la época, en un país que se hallaba bajo el gobierno de una dictadura militar.

El contexto de debate en esos momentos se inscribía en torno al progreso urbano. Con una crítica a la concepción de que la destrucción de "lo viejo (el pasado)", y la conservación solo de aquellos edificios monumentales, posibilitaba "construir ciudad", se fomentaba la recuperación de áreas en tanto espacios con valor arquitectónico y simbólico para los ciudadanos (Gómez; Zunino Singh, 2008, p. 339).

A partir de una preocupación por el destino y la preservación de las piezas rescatadas de los edificios que se demolían para proseguir con el ensanche de la Avenida 9 de Julio5, se crea el 25 de octubre de 1968 el "Museo Edilicio", luego denominado "Arquitectónico", e inmediatamente "Museo de la Ciudad", ejerciendo como director el arquitecto J. M. Peña (Peña, 2003, p. 13). No obstante, el interés por la 
recuperación de aquellos elementos considerados "identitarios" de los habitantes de la ciudad, no provino de un ente gubernamental, sino de un particular (J. M. Peña ${ }^{6}$ ). Éste, a través del encadenamiento de una serie de "situaciones aleatorias" y relaciones sociales con círculos cercanos al poder político (esencialmente autoridades municipales) logra la creación de una institución museística.

Las vinculaciones mantenidas entre J. M. Peña y el poder de facto (básicamente con sus funcionarios a nivel municipal - hoy gobierno autónomo de la Ciudad -) se articulaban en realidad a través de su participación en algunos círculos sociales compartidos y en los cuales se generaban relaciones - en este caso superficiales - pero que implicaban un reconocimiento personal que "situaba" a los sujetos en uno de los polos de la dicotomía ideológica establecida y sostenida violentamente por la dictadura militar (partidarios/adeptos al Gobierno de facto-enemigo interno/terroristas). Cabe señalar también que el interés del estado y su voluntad de inversión en el proyecto, eran extremadamente limitados, y que se consideraba además que un Museo refería al campo cultural (entendido como ámbito carente, "vacío y escindido de toda ideología", aludiendo a una institución "legítima" e inocua políticamente.

En tal sentido, las estructuras políticas no son monolíticas y admiten de hecho (en este caso básicamente en temas estimados "insustanciales" y "no peligrosos" por el régimen de facto gobernante), la acción de sujetos operando para la creación, funcionamiento y/o transformación de espacios (aquí referidos al campo de la cultura y el patrimonio), en tiempos y lugares específicos, siendo los órganos estatales, permeables en tales ocasiones a la "microfísica del poder" (Arantes, 1997, p. 278, 286).

De todos modos, si bien el tipo de ámbito creado: un Museo y los objetivos de su director: "traer al presente" y recuperar la "propia historia", no resultaban revulsivos ni inquietantes respecto de los lineamientos ideológicos del gobierno de facto, en los hechos, las concepciones que sostenía Peña sobre aquello que conformaba el campo de la cultura y del patrimonio, acerca del carácter que debían poseer los elementos exhibidos y la modalidad de presentación de las 
muestras museísticas, se alejaba de la visión "oficial". Las exhibiciones sobre sucesos y héroes habilitados por la historia "legítima", o bien quedaban en un segundo plano o bien se presentaban al público, pero privilegiando sus aspectos más cotidianos y corrientes; se ampliaba la conceptualización del patrimonio hacia otras categorías heterogéneas de referentes.

La institución expandía sus propuestas, comprendiendo piezas que formaban parte de los hábitos, usos y prácticas que referían a la vida doméstica y a la "intimidad" de los sectores de la sociedad más acomodados, pero incluyendo asimismo materiales que daban cuenta de costumbres, actividades y expresiones cotidianas de sectores populares; esta práctica se mantuvo a lo largo de los años. En una entrevista realizada por un periodista de un diario local al Director del Museo, el primero explicaba que las colecciones se caracterizaban por su "heterogeneidad", comprendían elementos publicitarios, juguetes, baldosas, muebles, libros escolares y otros), y las exposiciones igualmente abarcaban temas disímiles, se realizó p.e. la primera exhibición de envases, titulada "Los envases de la nostalgia", otra, denominada "Estos despojos maravillosos", en la que se exhibía desde una petaca de cuero crudo del siglo XVIII, hasta un tapiz tipo Pompadour abandonado en la demolición de la autopista 25 de Mayo (Kiernan,1999).

Se trataba de dar cuenta de "épocas pasadas" - de un pasado que anclaba primariamente en el barrio -, atendiendo a aquellos elementos que expresaban y reforzaban una "identidad barrial, citadina, local y constitutiva de aquella nacional". En tal sentido, había diferencias con la posición sostenida desde el ámbito gubernamental, que privilegiaba el patrimonio histórico-arquitectónico - monumentalista; pero además, en este proceso, el director de la institución - si bien no radicalmente -, mantenía sus diferencias con la perspectiva estatal-oficial sobre la historia, la cultura y el patrimonio.

Acorde a lo dicho, entendemos que tanto la creación del Museo, como posteriormente de la Feria de Antigüedades, se conformado contando con la anuencia de las autoridades del gobierno de facto, y asimismo a contrapelo de las condiciones y concepciones ideológicas que imponía el contexto político del período; coexistieron en tal proceso, 
nociones, entendimientos y sentidos disímiles en gran medida, sobre la cultura y el patrimonio, por parte de ambos actores sociales.

La institución, si bien se propuso lograr el reconocimiento del patrimonio histórico arquitectónico de Buenos Aires, conjuntamente determinó que su objetivo consistía en

[...] documentar, investigar y mostrar la historia y las costumbres de la ciudad a través de los hechos generados, y que generan, día a día, los habitantes de la ciudad. Para que esto fuese posible fue necesario tener en cuenta que nada debía dejarse de lado en la vida de relación. Quedó claro entonces que para el caso es tan valioso un botón como una tarjeta postal, un mueble, una revista o una melodía. Los edificios son valiosos, sin ninguna duda, pero es preciso tener muy en claro que estos son el resultado y la respuesta a necesidades y circunstancias socioculturales, las costumbres y la vida de relación. (Peña, 2003, p. 13-14)

Se pretendía "posibilitar" al público el conocimiento y reconocimiento de aquellas prácticas propias de los pobladores de antaño, trascendiendo los aspectos edilicios y comprendiendo sus formas de vida y su cotidianeidad, las cuales se consideraba que estaban transitando un "acelerado proceso de desaparición y olvido", operando los funcionarios del Museo desde una "retórica de la pérdida" ( Santos Gonçalves, 2002).

Se posicionaba fuertemente como un pilar de la institución, el aspecto educativo, didáctico; desde una concepción en la cual los habitantes de la ciudad debían ser instruidos sobre su propia historia, asistidos en la construcción de su identidad y en el proceso de articulación, reconocimiento y generación de sentido de la nacionalidad

Se trataba no solamente de evitar que se destruyeran y abandonaran objetos, bienes y expresiones que remitían a la historia de la ciudad, sino de "formalizar su legitimidad patrimonial"; y la misma se plasmaba plenamente a partir del reconocimiento que suponía su exhibición en un Museo, ámbito institucional, cultural, creador y reproductor de sentido, sitio en el cual se instituye y refuerza la historia y el pasado oficial y legítimo, espacio donde se construye y reproduce patrimonio, en tanto representación de la identidad y de la nacionalidad. 
Cabe agregar que desde su creación y durante el período al frente de la institución (mediados del año 2006), la gestión del director del Museo tuvo un carácter personalista; sus concepciones sobre la urbe, la historia, la memoria, el patrimonio, la identidad, marcaron la orientación que asumiría la institución y signaron con su impronta las peculiares características del mismo. Se puso en juego el "saber experto", el "discurso autorizado" (Smith, 2006), el conocimiento poseído por los especialistas, los idóneos, el cual institucionaliza el Estado, los organismos internacionales, las agencias culturales y las instituciones académicas.

Desde la dirección del Museo se esgrimió un discurso patrimonial vinculado estrechamente (como ya mencionamos) a la historia, y a la valoración y recuperación de la memoria, siendo ésta última considerada un tema clave ${ }^{7}$, y refiriendo J.M. Peña a la misma indistintamente como "memoria colectiva" o "memoria histórica" (Entrevista de la autora al funcionario el 8 de marzo de 1990).

Por otra parte, cabe tener presente que los debates sobre" las relaciones entre memoria e historia" han conformado un tema relevante no solo a nivel historiográfico, sino de las ciencias sociales en general ${ }^{8}$. Pierre Nora planteó en sus trabajos (1984, 1986 y 1992, los cuales fueron publicados luego en una obra colectiva, bajo su dirección), que Memoria e Historia funcionan en dos registros totalmente diferentes, aun cuando es evidente que mantienen estrechas vinculaciones. Cabe retomar puntos centrales de la posición del autor, respecto de la relación y diferencia entre ambas.

[...] funcionan en dos registros radicalmente diferentes, aun cuando es evidente que ambas tienen relaciones estrechas y que la historia se apoya, nace, de la memoria. La memoria es el recuerdo de un pasado vivido o imaginado. Por esa razón, la memoria siempre es portada por grupos de seres vivos que experimentaron los hechos o creen haberlo hecho. La memoria, por naturaleza, es afectiva, emotiva, abierta a todas las transformaciones, inconsciente de sus sucesivas transformaciones, vulnerable a toda manipulación, susceptible de permanecer latente durante largos períodos y de bruscos despertares. La memoria es siempre un fenómeno colectivo, aunque sea psicológicamente vivida como individual. Por el contrario, 
la historia es una construcción siempre problemática e incompleta de aquello que ha dejado de existir, pero que dejó rastros. A partir de éstos, controlados, entrecruzados, comparados, el historiador trata de reconstituir lo que pudo pasar y, sobre todo, integrar esos hechos en un conjunto explicativo. La memoria depende en gran parte de lo mágico y sólo acepta las informaciones que le convienen. La historia, por el contrario, es una operación puramente intelectual, laica, que exige un análisis y un discurso críticos. La historia permanece; la memoria va demasiado rápido. La historia reúne; la memoria divide. (Pierre Nora, entrevista de Luisa Corradini, en periódico La Nación, 15 de marzo de 2006)

Para el director de la institución museística, tal "memoria común" comprendía básicamente aquellos recuerdos, imágenes fracturadas y espontáneas del pasado que se consideraba atesoraban los pobladores y que debían ser recuperadas y preservadas, dado que contribuían a la construcción de una identidad colectiva y compartida. El siguiente planteo de LaCapra (2009, p. 33) contribuye a situar la concepción expuesta:

Aún con sus falsificaciones, represiones, desplazamientos y negaciones, la memoria puede llegar a ser informativa no en términos de una representación empírica de su objeto sino como la recepción y asimilación [...] de ese objeto tanto por los participantes en el acontecimiento como por quienes nacieron después.

Desde una postura que entiende que la memoria no es idéntica a la historia, pero tampoco su opuesto, se plantea que esta relación varía a lo largo del tiempo y que la primera es una fuente fundamental para la segunda. LaCapra plantea que ambas mantienen una relación suplementaria, base para una interacción mutuamente cuestionadora o para un intercambio dialéctico que nunca tenderá a una clausura absoluta. Así como la historia difícilmente pueda captar los componentes emocionales de las experiencias, ésta abarca elementos que no se agotan en la memoria, tales como factores económicos, demográficos, etc. (LaCapra, 2009, p. 34).

Por otra parte, la invocación a la historia, por parte del Museo, apelaba a aquella "oficial", fáctica, "objetiva"; considerada una 
representación del pasado, una reconstrucción de lo que ya no es (Nora, 1984), la cual operaba como marco, en parte, de sus exposiciones y actividades. Tal apelación, se aunaba sin dificultades con una concepción de memoria (a la cual se le otorgaba centralidad), comprendida como repositorio de recuerdos de tiempos pasados, de reconocimiento de vivencias, emotiva, acreditadora de pertenencia y conformadora de identidades.

Conceptos ambos: historia y memoria, que en una reflexión desde los sujetos involucrados y situada en una agencia institucional se ponían en juego complementariamente, construyendo y expresando una posición específica respecto (de los usos) del pasado.

\section{El Museo en la Calle: La Feria de San Pedro Telmo}

A comienzos de los 70', desde el Museo de Ciudad se propuso la creación de la Feria de Antigüedades denominada "Feria de San Pedro Telmo". Desde el Municipio no se puso ningún tipo de reparo a su instalación y fue inaugurada en noviembre de 1970, en la Plaza Dorrego (calles Defensa y Humberto Primo), acentuándose el hecho de que

[...] su presencia haría que los habitantes de la ciudad descubrieran o redescubrieran el viejo barrio y su historia, [y destacándose que] todo lo que en ella se vendería formó parte alguna vez de la vida cotidiana de Buenos Aires [...]. Su aparición significó un llamado de atención hacia aquellos objetos que habían quedado olvidados en altillos, cajones o sótanos por ser considerados pasados de moda y sin aparente interés. (Peña, 2003, p. 63)

La Feria, dependería del Museo, comenzando su funcionamiento con 30 puestos; dos meses después el número creció a 265, dando cuenta del éxito que tuvo la misma. Cabe agregar que este ámbito dio lugar a la instalación allí de un número pequeño de artesanos, dado que se había acordado que éstos conformarían un porcentaje muy menor respecto de los otros puesteros que exhibían y comercializaban los rubros de interés de la institución, ligados a las "antigüedades".

Paralelamente, el Museo se ocupó de difundir la historia y el anecdotario de los edificios y calles vecinas a la Plaza, llevando a cabo 
visitas guiadas y apuntando a que el barrio sur fuera "recuperando su presencia en el imaginario popular" (Peña, 2003, p. 63).

La Feria mantenía las mismas concepciones que conformaron el espíritu de la propuesta museística, aunque con las especificidades que imponía el hecho de tratarse de un "ámbito ferial".

Funcionando solamente los días domingo, se exhibía para la venta una variedad de objetos "antiguos" de todo tipo, que proponían “... un inesperado viaje a los recuerdos y al encuentro con la memoria de la ciudad" (Peña, 2003, p. 67). La Feria se constituyó en un atractivo relevante a nivel nacional e internacional.

Por otra parte, paulatina y progresivamente, se fueron instalando en sus alrededores comercios de anticuarios.

Como ya mencionamos, el Municipio no puso objeciones a la instalación de esta Feria que funcionaba en un espacio público de la ciudad. Bajo un gobierno de facto, tales zonas se pretendían "vacías"; su ocupación "periódica" (el armado de los puestos se llevaba a cabo cada domingo) por "trabajadores", más la presencia itinerante del público (habitantes de la ciudad y turistas) implicaba una concentración humana vislumbrada como potencialmente peligrosa desde la tiranía que gobernaba el país. La Feria funcionó no obstante, sin inconvenientes, ni represiones, haciendo un uso semi-permanente de un ámbito público.

\section{Expresiones Culturales Heterodoxas en Tensión - El Patrimonio Impugnado}

Durante el período en que se desarrollaron los procesos precedentes, hacia fines de los 60 se conforman en la Ciudad de Buenos Aires las primeras Ferias de artesanías "urbanas" realizaciones, conformando una propuesta estética-expresiva, con carácter simbólico y viabilidad económica.

Su concreción resultó compleja y conflictiva en relación con los poderes públicos. Frente a la fragilidad "legal" de la situación, los artesanos obtuvieron inicialmente un permiso "habilitante" (de contenido difuso) concedido por la Dirección de Parques y Paseos de la entonces Municipalidad de la Ciudad de Buenos Aires (MCBA), el cual posibilitó que un grupo de trabajadores se instalara en el predio 
de la plaza Intendente Alvear (más conocida como Plaza Francia). La forma en que se materializa este hecho, las dificultades habidas, el carácter irregular del "permiso habilitante" en los planos legal y administrativo, se enmarcan en el contexto político del período, de los poderes de facto que gobernaban el país. Los prejuicios sobre sujetos, espacios y eventos no convencionales, la negación de las "producciones culturales no legitimadas previamente", permeaban el vínculo con el poder local.

En la búsqueda de una organización más estable los artesanos realizaron entonces contactos con las autoridades del Museo de la Ciudad, ya que había una relación previa con su director. Éste elevó la problemática al Intendente de la ciudad, quien decidió que dicha institución reorganizara la Feria y en adelante se hiciera cargo de ella. Tal intervención, por fuera de los canales formales y basada en relaciones personales con funcionarios del gobierno militar, fue la "llave" para la instalación de la primera Feria artesanal. La gestión del arquitecto J.M. Peña se inició hacia mediados de setiembre de 1971y culminó en 1974 cuando éste se desvinculó de la misma.

El denominado "Sistema de Ferias" de la Ciudad se fue constituyendo mediante la ocupación de espacios públicos (plazas y parques de la ciudad, en su casi totalidad) en los cuales los artesanos de la urbe, exhibían y vendían su producción. Se conformaron así "Ferias artesanales" que fueron habilitándose progresivamente. Se integró con los ámbitos de Plazoleta Santa Fe (en Plaza Italia), Vuelta de Rocha (en La Boca), Plaza intendente Alvear (denominada más comúnmente Plaza Francia), Parque Centenario (barrio de AlmagroVilla Crespo), Plaza Manuel Belgrano (en Belgrano), Parque Lezama (en Barracas), Plaza Doctor Bernardo Houssay (en Barrio Norte-zona de instituciones/Facultades de la UBA). Se rigió por la Ordenanza n. 28.702/74 (primer instrumento jurídico con que contaron los espacios feriales y su producción), la cual fue derogada en 1976, con la asunción de la última tiranía militar. El "Sistema de Ferias" de la Ciudad dispuso de una reglamentación específica y gran parte de sus normativas laborales se debieron directamente al aporte de los artesanos. Con el tiempo, se sucederían nuevas Ordenanzas fijando reglas para tales espacios (Rotman, 2000). 
El proceso ferial artesanal implicó a lo largo del tiempo, aperturas, clausuras, desplazamientos, intentos forzosos de traslado, etc. hasta la instauración de un régimen democrático en el país, en 1983. No obstante, en los 90', con un gobierno "neo-liberal" las Ferias vieron comprometida nuevamente su persistencia y funcionamiento.

Las características "novedosas" que presentaban los bienes exhibidos (en relación con otras realizaciones de carácter artesanal) consistía en la intencionalidad de los productores de aunar en la elaboración de las piezas una preocupación por el diseño, con una clara idea de lo plástico, el dominio y conocimiento exhaustivo del material y de la técnica a partir de una tecnología predominantemente manual, mostrando habilidad creativa y originalidad. Su establecimiento instalaría fuertemente a tales ámbitos de exhibición y comercialización y a su producción como parte del movimiento cultural de la ciudad, ubicados en las plazas y parques de la urbe (Rotman, 2003).

Las Ferias fueron adquiriendo notoriedad y cobrando relevancia como ámbito innovador dentro del paisaje cultural de la ciudad. En poco tiempo la Feria inicial (Plaza Francia), se convirtió en una experiencia exitosa, con profusión de público y amplia cobertura de los medios. De este hecho dieron cuenta los periódicos de la época (La Opinión, 27/8/72, Clarín, 17/10/72, y también El Diario 7/5/72, éste último de Montevideo), e incluso un programa televisivo de amplia audiencia en la época ("Sábados Circulares", conducido por Nicolás Mancera) transmitió toda una tarde desde la Plaza realizando entrevistas a artesanos y público (Rotman, 2004).

Hacia el 74' (ya iniciado el breve gobierno democrático - que continuaría hasta 1976), las Ferias pasan a depender de la “División de Artesanía", creada a tales fines, e inserta en la "Secretaría de Cultura de la MCBA". Ahora bien, la inserción en dicha repartición, no modifica ciertos supuestos sobre las Ferias: los organismos gubernamentales continuaban expresando dificultades para considerar a los espacios feriales como culturales; tal tipo de emplazamiento no habilitaba su consideración como "espacios de cultura". Ámbito, productores (parte integrante "supuestamente" de los sectores subalternos) y bienes, no encuadraban en sus categorías clasificatorias, para ser considerados parte 
del campo artístico, histórico o cultural; predominaba en las instancias de gobierno un concepto restringido y elitista de la cultura, incompatible con una validación de las artesanías urbanas. Del mismo modo, si la inserción de tales producciones se presentaba problemática en tal área, resultaba impensable su valorización y reconocimiento como referentes patrimoniales. Se dotó de carácter negativo una expresión cultural considerada "ilegítima", y que resultaba excluida en consecuencia de toda participación en la conformación de un patrimonio nacional. La "puesta en valor" de un bien seleccionado para tales fines, no refiere solamente a una cuestión clasificatoria, sino que conlleva siempre un fuerte contenido ideológico (Martin; Rotman, 2005) y se vincula en este caso con una visión limitada y parcial que se tiene desde las instancias decisionales, de los conceptos de historia y de patrimonio.

Por tanto, la inexistencia de políticas patrimoniales en el período, puede leerse no como carencia sino como la manifestación de la intencionalidad que implicaría la "no política". Las concepciones estatales sobre el tema giraban en torno a dimensiones ideológicas y políticas, en los gobiernos de facto prioritariamente; en gobiernos democráticos se ha tratado más bien de ignorancia sobre la problemática, prejuicios, falta de interés y apatía.

De la misma manera, no hubo ningún tipo de reflexión en torno a lo que expresaban las Ferias artesanales respecto de la ciudad y sus habitantes, y tampoco el propósito de fijar una direccionalidad sobre temáticas, temporalidades, sobre aquello que se quería "mostrar" en tanto "recorte" identitario y representativo de la urbe, su historia y sus pobladores. Resultaba impensable el reconocimiento de la condición de "productores culturales" de los artesanos y de las Ferias como elementos "distintivos y peculiares" de la urbe y "testimonios referenciales" de su pasado "reciente".

Además, tales ámbitos, casi desde sus orígenes, estuvieron supeditados a distintas reparticiones de la M.C.B.A., y aun habiendo circulado por distintas agencias, mayoritariamente subordinadas al área de Cultura, la dependencia de las Ferias, fungió como una vinculación formal, una manifestación con carácter retórico, vacía de contenido y lo que resulta más grave, sin convicción ninguna por parte del estado. 
Es más, para el gobierno de facto se trataba de ámbitos que debían ser objeto de control, dado que toda su impronta "se corría" de los canales "usuales/normales" ("aspecto" de los feriantes, carga imaginaria que conllevaba su condición de "artesanos", asentados en "plazas" de la ciudad, venta de "bienes difíciles de clasificar") y además sin "garantes" cercanos al poder que dieran cuenta de ellos. Constituían el "otro", desconocido y "peligroso", que debía ser observado, confrontado y objeto de control; siendo esta situación históricamente percibida por los artesanos.

Cabe tener presente, que la complejidad y conflictividad han caracterizado sistemática e históricamente el vínculo feriantes-estado local. La tensión cuasi permanente habida durante los gobiernos de facto, tuvo ribetes dramáticos a partir del 76'. Durante la última dictadura militar, - y sumado a la atrocidad de sus prácticas -, en las Ferias se produjo el desmantelamiento directo de algunas de ellas, permanentes traslados forzosos y trágicos hechos de violencia y violación de derechos humanos.

Las categorías de memoria e historia, muy presentes en el caso anterior, aquí directamente no tuvieron cabida; referían totalmente a otro plano, ajeno a esta problemática.

Igualmente, las Ferias artesanales no contaban con agencias políticas proclives a su activación, ni con actores sociales "inobjetables, ni "calificados positivamente" por el gobierno - sin poder no hay patrimonio (Prats, 1997).

Ahora bien, si el patrimonio no existe, como sostiene Prats (1997), más que cuando es "activado", es decir cuando se promueve una versión específica de una determinada identidad, seleccionando, interpretando y representando un conjunto de referentes ad hoc, y si los poderes políticos constituyen en primer lugar las instancias "activadoras" de repertorios patrimoniales, se tornan visibles las dificultades del estado para legitimar como patrimonio, bienes y eventos desvalorizados sistemáticamente (Rotman, 1999), al tiempo que el Museo de la Ciudad y la Feria de Antigüedades eran reconocidos y habilitados en su carácter cultural. 
Toda sociedad fija (a través de los sectores dominantes) una jerarquía respecto de los referentes patrimoniales, en la cual las producciones de los grupos subalternos tienen un lugar subordinado en las instituciones y los dispositivos hegemónicos. La situación de los artesanos urbanos, no hace más que visibilizar como las cuestiones de poder son constitutivas en la conformación (y apropiación) del patrimonio, entendiendo que éste es un espacio de confrontación, a ser pensado en términos de construcción social y como acción política (Pereiro Pérez; Sierra Rodriguez, 2005; Cruces, 1998).

Ahora bien, los feriantes de San Pedro Telmo también formaban parte mayoritariamente de los grupos subalternos, trabajando además en un espacio público de la ciudad; no obstante en ese caso, no sufrieron las mismas presiones ni desvalorización que los artesanos feriantes urbanos. La íntima vinculación y dependencia del Museo los legitimaba o mínimamente los tornaba inocuos para la "seguridad nacional", o bien, considerados como una extensión del mismo, éste los cubría con su manto de institucionalidad.

\section{Consideraciones Finales}

Analizamos comparativamente en este trabajo dos casos, situados en la Ciudad de Buenos Aires y originados a fines de los 60': el "Museo de la Ciudad" y la "Feria de San Pedro Telmo" (de Antigüedades) y las "Ferias Artesanales del "Sistema de Ferias", dependientes del entonces Municipio de la Ciudad, hoy Gobierno Autónomo. La propuesta se ha ubicado en el campo de la cultura y el patrimonio, interesándonos en las "marcas" que el contexto social, político e ideológico en el cual se insertan los ámbitos examinados, imprime sobre los mismos, así como en las formas en que se manifiesta la "desigualdad" y se ejerce el poder en dicho campo; aclarando que durante el período abarcado (y salvo contadas etapas), el país se ha encontrado bajo gobiernos de facto.

Ahora bien, creados en el mismo período, son contrastantes los procesos seguidos por el Museo de la Ciudad y la Feria de San Pedro Telmo y las Ferias de Artesanías urbanas. Su análisis muestra la distinta valoración por parte del estado, de los espacios, de las características de los eventos y de los sujetos intervinientes, así como la heterogénea 
apreciación de ámbitos y bienes; y expresa las concepciones que sobre la cultura y el patrimonio han mantenido los poderes gubernamentales (básicamente los gobernantes de facto.

Respecto de la creación del Museo, ello involucró un ámbito no visualizado en esos momentos por el estado, como político e ideológico y potencialmente "peligroso"; se trataba de una institución museística y una temática a primera vista inocua; fungieron en este caso, como tópicos relevantes, explícitos y redundantes, una apelación constante al pasado, a la memoria y a la historia, vinculados con la idea de la nacionalidad y la identidad colectiva. Y es interesante que incluso hubo lugar en el Museo para una apertura en los contenidos patrimoniales, la cual no fue cuestionada por el gobierno de facto; se sumaba a ello, las relaciones sociales no negativas y ocasionales, mantenidas entre el impulsor del proyecto y las autoridades locales.

Asimismo, como ya planteamos, la presencia de la Feria de Antigüedades funcionando en un espacio público (ámbitos altamente recelados por las autoridades militares y vedados a la realización de todo evento que implicara concentración humana e interacción social) se comprende desde su dependencia vital con el Museo - institución cultural y patrimonial por excelencia. Con una lógica, una temática y bienes en común, referenciaban aquel pasado que se valorizaba y cuya memoria se pretendía fuera recuperada y apropiada por los vecinos de la Ciudad, siendo considerada en definitiva un complemento, una extensión no conflictiva del Museo. Es más, algunos vendedores se vestían y caracterizaban como sujetos de épocas pasadas (lo continúan haciendo en la actualidad), pero ello se consideraba "vistoso", "atractivo"; lejos de desentonar, se ubicaba en línea con las propuestas de la institución. Es dable sugerir, que la "legitimidad" (condición atribuida e "indiscutida" de las entidades culturales), es un atributo que "circula", es pasible de ser compartida y transmitida, disponiéndose en cada caso las vías más aptas para consumar tal transferencia. Museo y Feria de Antigüedades “convivieron" sin conflictos con el poder gubernamental estatal; allí no hubo disputa. La propuesta no resultaba revulsiva ni contestataria para los poderes públicos. La estrecha vinculación con el Museo en definitiva, habilitaba plenamente al espacio ferial y garantizaba su 
reconocimiento y resguardo; operaba simbólicamente como entidad, como red protectora para ésta, respecto de iniciativas, procedimientos y medidas de fuerza que pudieran provenir del estado.

En tal sentido, las Ferias artesanales urbanas tuvieron otro tipo de recorrido. No contaron con un organismo "mediador" - considerado culturalmente "legítimo"- entre ellas y las agencias gubernamentales. Para éstas, el reconocimiento y la búsqueda de legitimidad adquirieron permanentemente el carácter de disputa, de conflicto con el estado y sus concepciones sobre la cultura y patrimonio. Hemos planteado la desestimación por parte del gobierno local hacia productores y bienes, así como la limitada capacidad de los poderes públicos para ampliar/modificar sus categorías clasificatorias, negándose además a reconocer su condición de referentes representativos de la ciudad, de la cultura citadina. Asimismo, el sitio de exhibición de las producciones artesanales - una Feria sita en un lugar público (plaza/parque) - no exhibía credenciales legitimadoras de "ámbito de la cultura", como si las presentaba la Feria de San Pedro Telmo, vía Museo de la Ciudad.

Surgidos en el mismo período, y bajo un gobierno dictatorial, ambos espacios culturales dan cuenta de trayectorias dispares. En tales procesos, el estado, a través de instancias intermedias, se constituye necesariamente como actor vital en la planificación y gestión de la cultura y el patrimonio; el tema en tal sentido es de carácter político.

\section{Notas}

1 Antropologías centrales y periféricas, las denominará Cardoso de Oliveira (2000); también Restrepo (2006); Lins Ribeiro y Escobar se referirán a otras antropologías, (2006); Stocking aludirá a Empire building y Nation-building (1982); Archetti planteará además la existencia de jerarquías entre ellas (2006).

2 Cabe señalar, por otra parte, que en América Latina, y sobre tópicos patrimoniales específicos, diferentes países reconocen, toman conocimiento y como guía modalidades organizativas institucionales y operativas de alguno de sus estados. Tal es el caso del reconocimiento hacia la labor llevada a cabo por Brasil en tales temas, tomado por otras naciones de la región como modelo para el diseño de legislación y políticas patrimoniales (p.e. Ecuador, Argentina, Perú, entre otros, aunque con resultados disímiles).

3 Entendemos que estamos estableciendo una comparación entre un evento ferial y una institución museística con una Feria como apéndice, las cuales poseen distintas características, disímiles lógicas de funcionamiento y función y son valoradas diferencialmente por parte de los funcionarios de organismos estatales y amplios 
sectores de la sociedad civil. No obstante, en este caso, el Museo de la Ciudad con la Feria de San Pedro Telmo y las Ferias Artesanales de la Ciudad de Buenos Aires presentan en el período histórico tratado, características tales que entendemos justifican el análisis propuesto.

4 Sobre las vinculaciones entre la constitución de espacios públicos, planificación urbana- centros históricos y patrimonio consultar entre otros: Sosa (2010), Girola et al. (2013).

5 En noviembre del año 1967 fue creada una Comisión Técnica Municipal para seleccionar todo aquello que constituyera un testimonio de la arquitectura porteña (Peña, 2003, p. 13).

6 No resguardamos su identidad bajo una identificación ficticia, tal como procedemos metodológicamente en nuestra disciplina, dado que se trata de un personaje reconocido por su extensa actuación pública y fallecido en 2015.

7 Se ha generado una amplia discusión teórica y debates en torno de tal concepto, que remite inicialmente a Maurice Hallbwachs, 2004 [1950], y al cual en ocasiones se alude como "memoria histórica", siendo objeto de diferentes definiciones. A posteriori de los planteos iniciales del autor, se produjeron ricas y productivas propuestas teóricas - ver entre otros: Elder (1981), Johnson et al. (1982), Hobsbawm y Ranger (2002) e Ganguly (1992).

8 Se encuentra una amplia bibliografía y diversidad de discusiones al respecto - ver entre otros: Handler e Linnekin (1984); Todorov (2000), Candau (2002; 2007) e Huyssen (2002).

9 Tal denominación conforma una categoría nativa, la cual ha sido progresivamente utilizada como término clasificatorio por parte de los investigadores; aquí mantenemos el vocablo, el cual se vincula, asimismo con la conceptualización de (Lauer, 1984, p. 61).

\section{Referências}

ARANTES, Antonio. Patrimonio cultural e Nacao. In: CARNEIRO ARAUJO, Angela Maria. (org.). Trabalho, cultura e cidadania. Sao Paulo: Scritta, 1997. p. 275-290.

ARCHETTI, Eduardo. How many 'centers' and 'peripheries' in anthropology? A critical view on France. In: LINS RIBEIRO, Gustavo; ESCOBAR, Arturo. (ed.). World Anthropologies: Disciplinary Transformations in Systems of Power. Oxford: Berg Publishers, 2006. p. 113-132.

CANDAU, Joël. Bases anthropologiques et expressions mondaines de la quête patrimoniale: mémoire, tradition et identité. 2007. Conferência presentada en el Ier Seminario Internacional en Memoria y Patrimonio - Universidad Federal de Pelotas, Pelotas, 2007.

CANDAU, Joël. La antropología de la memoria. Buenos Aires: Nueva Visión, 2002. 
CARDOSO DE OLIVEIRA, Roberto. Peripheral antropologies versus central antropologies. Journal of Latin American Anthropology, American Antropological Association, p. 10-30, 2000.

CLARÍN. Barbas y collares en Plaza Francia. Buenos Aires, 17/10/72. Medio Gráfico.

CORRADINI, Luisa. No hay que confundir memoria con historia, dijo Pierre Nora. En: La Nación: Entrevista a Pierre Nora. 15 de marzo de 2006. Disponible en: http://www.lanacion.com.ar/788817-NO-HAY-QUE-CONFUNDIRMEMORIA-CON-HISTORIA-DIJO-PIERRE-NORA. Acceso el: 5 jul. 2015.

CRUCES, Francisco. Problemas en torno a la restitución del patrimonio. Una visión desde la Antropología. Alteridades, [S.l.], n. 16, p.75-84, 1998. EL DIARIO MONTEVIDEO. Feria artesanal de la ciudad de Buenos Aires. Uruguay. 7/5/72. Medio Gráfico.

ELDER, Glen H. History and the Life Course. En: BERTAUX, Daniel (ed.). Biography and Society. The Life History Approach in the Social Sciences. London and Berkeley: Sage Publications, 1981. p. 77-115.

GANGULY, Keya. Migrant Identities: Personal Memory and the Construction of the Selfhood. Cultural Studies, [S.l.], v. 6, n. 1, p. 27-50, 1992.

GIROLA, Maria Florencia; GONZALEZ BRACCO, Mercedes; YACOVINO, Maria Paula. Procesos de constitución del espacio público en Buenos Aires desde una perspectiva etnográfica: el lugar del patrimonio urbano en la configuración contemporánea de tres barrios porteños. Papeles de Trabajo, Rosario: C.I.S.E.A. U.N.R., n. 25, p. 30-50, julio 2013.

GOMEZ, Mariana y Dhan ZUNINO SINGH. La (re) valorización de la zona sur y el patrimonio histórico-cultural como recurso turístico. In: HERZER, Hilda (ed.). Con el corazón mirando al sur. Transformaciones en el sur de la ciudad de Buenos Aires. Buenos Aires: Espacio Editorial, 2008. p. 325-367.

HALLBAUCH, Maurice. La Memoria Colectiva. Zaragoza: Prensas Universitarias de Zaragoza, 2004 [1950].

HANDLER, Richard; LINNEKIN, Jocelyn. Tradition, Genuine or Spurious. Journal of American Folklore, [S.l.], v. 97, n. 385, p. 273-290, 1984.

HOBSBAWM, Eric; RANGER, Terence (ed.) La invención de la tradición. Barcelona: Crítica, 2002 [1983]. 
HUYSSEN, Andreas. En busca del futuro perdido. Cultura y memoria en tiempos de globalización. México: Fondo de Cultura Económica, 2002.

JOHNSON, Richard et al. (Eds). Making Histories: Studies in Historywriting and Politics. Minneapolis: University of Minnesota Press, 1982.

KIERNAN, Sergio. El patrimonio es para gozarlo, no para sufrirlo. Entrevista a J. M. Peña. Página 12, 2015 [4 de octubre de 1999]. Disponible en: http://www.paginal2.com.ar/1999/99-10/99-10-04/PAG12. HTM. Acceso el: 16 set. 2015.

KROTZ, Esteban. La generación de teoría antropológica en América Latina: Silenciamientos, tensiones intrínsecas y puntos de partida. Maguaré, Colombia: Universidad Nacional de Colombia, n.11-12, p.25-39, 1996.

KROTZ, Esteban. La producción de la antropología en el Sur: características, perspectivas, interrogantes. Alteridades, México, Distrito Federal: Universidad Autónoma Metropolitana Unidad Iztapalapa, v. 3, n. 6, p. 5-11, 1993.

LA OPINIÓN. Buenos Aires, 27/8/72. Medio Gráfico.

LA PRENSA. Feria artesanal de la ciudad de Buenos Aires. Buenos Aires, 23/04/72. Medio Gráfico.

LACAPRA, Dominik. Historia y memoria después de Auschwitz. Buenos Aires: Prometeo, 2009.

LAUER, Mirko. Notas sobre la modernización de la artesanía en América Latina. Allpanchis, Cuzco: Instituto de Pastoral Andina, v. 20, n. 23, p. 61, 1984.

LINS RIBEIRO, Gustavo; ESCOBAR, Arturo. Las antropologías del mundo. transformaciones de la disciplina a través de los sistemas de poder.

Universitas humanística, Colombia: Pontificia Universidad Javeriana, n. 61, p. 15-49, enero-junio de 2006.

MARTIN, Alicia; ROTMAN, Mónica. Introducción. In: ROTMAN, Mónica; MARTIN Alicia (ed.). Dossier Cultura y Patrimonio: perspectivas contemporáneas en la investigación y la gestión. Cuadernos de

Antropología Social, Buenos Aires: Instituto de Ciencias Antropológicas, Facultad de Filosofía y Letras, Universidad de Buenos Aires, n. 21, p. 7-15, 2005.

NORA, Pierre. Entre Memoria e Historia: La problemática de los lugares". In: NORA, Pierre (Dir.). Les Lieux de mémoire, 1: La République. Paris: Gallimard, 1984. p. XVII-XLIL. 
PEÑA, José María. Museo de la Ciudad. Colección Cuadernos Educativos, Buenos Aires: Comisión para la Preservación del Patrimonio Histórico Cultural de la Ciudad de Buenos Aires, 2003. Disponible en: www.folkloretradiciones.com.ar/literatura/Museo_de_la_ciudad.pdf. Acceso el: 5 ago. 2015.

PEREIRO PÉREZ, Xerardo; SIERRA RODRIGUEZ, Xosé Carlos. Introducción. In: SIERRA RODRIGUEZ, Xosé Carlos; PEREIRO PÉREZ, Xerardo (coord.). Patrimonio cultural: Politizaciones y Mercantilizaciones. Sevilla: Fundación el Monte, FAAES, Asana, p. 9- 23, 2005 .

PRATS, LLorenc. Antropología y Patrimonio. Barcelona: Ariel, 1997. PRIMERA PLANA. Buenos Aires, 09/08/73. Artesanos. Ni Hippies ni faloperos. Medio Gráfico (Revista de Actualidad).

RESTREPO, Eduardo. Diferencia, Hegemonía y Disciplinamiento en Antropología. Universitas Humanística, Colombia: Pontificia Universidad Javeriana, julio-diciembre, n. 62, p. 43-70, 2006.

ROTMAN, Mónica. Cultura y Mercado: Prácticas de constitución y reproducción de eventos culturales y comerciales. ROTMAN, Mónica et al. (org. y comp.). Dossier Antropología de la Cultura-Cuadernos de Antropología Social, Buenos Aires: Instituto de Ciencias Antropológicas, Facultad de Filosofía y Letras, Universidad de Buenos Aires, n.1 1, p.47-64, 2000.

ROTMAN, Mónica. El reconocimiento de la diversidad en la configuración del patrimonio cultural: cuando las artesanías peticionan legitimidad. In: PAZ, Ester; TORRICO, Juan (comp.). Patrimonio cultural y Museología, Santiago de Compostela: FAAEE, 1999. p. 151-160.

ROTMAN, Mónica. Ferias de Artesanías en la Ciudad de Buenos Aires: memorias de una producción cultural urbana. In: MARONESE, Leticia (comp.). Temas de patrimonio - Primeras Jornadas de Artesanía Urbana como patrimonio cultural de Buenos Aires. Buenos Aires: Comisión para la preservación del patrimonio histórico-cultural de la Ciudad de Buenos Aires, Secretaría de Cultura, Gobierno de la Ciudad de Buenos Aires. v. 10, p. 17-30, 2004.

ROTMAN, Mónica. Modalidades productivas artesanales: expresiones de "lo local" en un mundo globalizado? Revista de Antropología Social CAMPOS, Edição Especial, Brasil: Universidad Federal de Paraná, n. 3, p. 135-143, 2003. 
SAntos GOnÇAlVES, Jose Reginaldo. A Retórica da Perda. Rio de Janeiro: UFRJ - Ministério de Cultura - IPHAN, 2002.

SMITH, Laranjane. Uses of Heritage. Londres: Taylor \& Francis e-Library. 2006.

SOSA, Victoria Ayelén. Planificación urbana y políticas de representación. El patrimonio como recurso de renovación urbana y espacio de confrontación en el casco histórico de Buenos Aires. In: ACTAS DEL XI COLOQUIO INTERNACIONAL DE GEOGRAFÍA. Buenos Aires: Universidad de Buenos Aires, 2010. Anais [...] Buenos Aires, 2010. STOCKING, George. Afterword: A view from the center. Ethnos, USA: University of Chicago, n. 47, p. 172-186, 1982.

TODOROV, Tzvetan. Los Abusos de la Memoria. Barcelona: Paidós, 2000 .

Recebido em 21/05/2018

Aceito em 19/09/2018 